\title{
GMR
}

\section{Effects of cartilage-derived morphogenetic protein 1 (CDMP1) transgenic mesenchymal stem cell sheets in repairing rabbit cartilage defects}

\author{
Y. Cui ${ }^{1}$, M. Yao ${ }^{1}$, Y. Liu ${ }^{1}$, L. Mu ${ }^{1}$, B. Zhang ${ }^{1}$ and G. Wu ${ }^{2}$ \\ ${ }^{1}$ Department of Otolaryngology, \\ The First Affiliated Hospital of Liaoning Medical College, \\ Jinzhou, Liaoning Province, China \\ ${ }^{2}$ Department of General Surgery, \\ The First Affiliated Hospital of Liaoning Medical College, \\ Jinzhou, Liaoning Province, China \\ Corresponding author: $\mathrm{G}$. Wu \\ E-mail: gangwudoc@163.com
}

Genet. Mol. Res. 15 (2): gmr.15028058

Received August 8, 2015

Accepted November 26, 2015

Published June 21, 2016

DOI http://dx.doi.org/10.4238/gmr.15028058

\begin{abstract}
The aim of this study was to investigate the abilities of cartilage-derived morphogenetic protein 1 (CDMP1) transgenic cell sheets in repairing rabbit cartilage defects. Rabbit CDMP1 transgenic bone marrow mesenchymal stem cell (BMSC) sheets (CDMP1-BMSCs) were cultured on temperature-sensitive culture dishes, and CDMP1 expression and type II collagen protein in the cell sheets were detected. Tissue-engineered cell sheets were constructed and transplanted into defect rabbit thyroid cartilage, to investigate the expression of engineered cartilage collagen protein and proteoglycan (GAG). The experiment was divided into three groups; A) BMSC sheet, B) Ad-CMV-eGFP-transfected cell sheet, and C) Ad-CMV-hCDMP1-IRES-eGFP-transfected cell sheet. The expression of CDMP1 was detected in the transgenic cell sheets. The
\end{abstract}


engineered cartilage exhibited positive immunohistochemical and Alcian blue staining. The expression levels of type II collagen protein and GAG in group $\mathrm{A}$ were positive, whereas those in group $\mathrm{B}$ and group $\mathrm{C}$ were negative $(\mathrm{P}<0.05)$. The CDMP1-BMSC sheets had a good cartilage differentiation activity, and could effectively repair rabbit laryngeal cartilage defects.

Key words: Cell sheet; Cartilage-derived morphogenetic protein 1; Bone marrow mesenchymal stem cell sheet; Adenoviral transfection; Cartilage tissue engineering

\section{INTRODUCTION}

Repairing trauma- and disease-caused cartilage defects is a problem faced by surgeons in clinical otolaryngology, head and neck surgery, and orthopedics. Tissue engineering has been considered an effective means to solve the problem of cartilage defects. Presently, this technology is able to build cartilage tissues with certain forms and volumes in vivo, and has achieved encouraging results in animal articular cartilage defect repairing experiments (Muraoka et al., 2013; Tamaki et al., 2013). However, it exhibits low cell utilization, including problems, such as scaffold degradation-caused fibrosis and nonspecific inflammatory responses, which has limited the development of tissue engineering. How to improve cell utilization, reduce immune rejections, and maintain the stability of the regenerated cartilage long-term, thus achieving true clinical application, have become the main problems needed to be solved in cartilage tissue engineering. Japanese scholars (Takezawa et al., 1990) used temperature-controlled materials to culture cell sheets. This avoids the digestive roles of enzymes, retains a large number of ligandin and growth factors, and, through overlapping construction, multilayer tissue sheets have been constructed that show structures more similar to natural cartilages (Takezawa et al., 1990). This technique has been widely used in various tissues such as myocardium, cornea and oral mucosa, etc. (Kobayashi et al., 2008; Fujita et al., 2012; Alshammary et al., 2013; Du et al., 2013). However, the exploration of cartilage reconstruction has progressed little and is particularly rare in transgenic cell sheets. Cartilage-derived morphogenetic protein 1 (CDMP1) is a polypeptide growth factor that has been much studied in recent years. It is mainly expressed in the developing cartilage core of long bones and in the precartilage matrix during the embryonic period. It has specific cartilage induction abilities and is therefore employed in repairing bone, tendon, ligament, and other tissues. Recently, Wu et al. (2014a,b) studied transfected CDMP and cell sheets in treating cartilage defects. They were able to show that CDMP-transfected bone marrow mesenchymal stem cells (BMSCs) have stronger abilities of cartilage repairing (Wu et al., 2014a,b). Hence, theoretically, CDMPtransfected BMSC sheets should have a strong ability of cartilage repairing. The present study builds on the previous studies by Wu et al. (2014a,b), aiming to investigate the capacities of CDMP1-BMSC sheets in repairing rabbit cartilage defects at genetic and protein levels.

\section{MATERIAL AND METHODS}

\section{Animals}

New Zealand white rabbits, $2.0-3.0 \mathrm{~kg}$ body weight, of both genders, were provided by 
Liaoning Medical Experimental Animal Center. This study was carried out in strict accordance with the recommendations of the Guide for the Care and Use of Laboratory Animals of the National Institutes of Health. The animal use protocol has been reviewed and approved by the Institutional Animal Care and Use Committee (IACUC) of Liaoning Medical University.

\section{Isolation and culture of BMSCs}

To anesthetize the New Zealand white rabbits, a 3\% pentobarbital sodium (Sigma-Aldrich Corp., MO, USA) was used $(30 \mathrm{mg} / \mathrm{kg})$ through ear vein injection. After a routine disinfection and the addition of paving towels, a bone marrow puncture was performed from the proximal ends of the bilateral femur (using a syringe with $0.2 \mathrm{~mL}$ heparin $200 \mathrm{U} / \mathrm{mL}$ ). Approximately 3-4 $\mathrm{mL}$ bone marrow was drawn to collect rabbit BMSCs using a density gradient centrifugation method. BMSCs were then inoculated in 10\% FBS-containing L-DMEM complete medium (Gibco Inc., TX, USA), and cultured at $37^{\circ} \mathrm{C}, 5 \% \mathrm{CO}_{2}$, and saturated humidity. The medium was changed for the first time after 3 days, followed subsequent changes every 2-3 days. When the cells reached 80 to $85 \%$ confluence, $0.25 \%$ trypsin (Sigma-Aldrich Corp.) was added for digestion and a cell passage with ratio 1:2 was performed.

\section{CDMP1-transfected BMSCs}

We used an adenovirus (Ad)-cytomegalovirus (CMV)-human CDMP1 (hCDMP1)internal ribosome entry site (IRES)-enhanced green fluorescent protein (EGFP) viral solution and an Ad-CMV-EGFP viral solution (Cyagen Biotechnology Co., Lid., Guangzhou) to transfect the BMSCs. This was done on 6-well plates with the multiplicity of infection (MOI) set to $50,100,150$, and 200 . To each well, we then added $2 \mathrm{~mL}$ basal medium, followed by overnight incubation at $37^{\circ} \mathrm{C}, 5 \% \mathrm{CO}_{2}$, and saturated humidity. The solution was then thoroughly washed with PBS (Sigma-Aldrich Corp.) and $2 \mathrm{~mL} \mathrm{10 \%} \mathrm{FBS-containing} \mathrm{L-DMEM}$ culture medium (Sigma-Aldrich Corp.) was then added for 2-5 days of continuous culture. Subsequently, the transfected cell morphology was observed under an inverted fluorescence microscope (Leica Science Lab., Berlin, Germany). The maximum MOI value that did not cause a significant cytopathic effect, was determined to be the best value for the target genecarrying adenovirus.

\section{Preparation of cell sheets}

The 4th-generation rabbit BMSCs were divided into three groups (Table 1). They were then transfected into BMSCs with MOI $=100$. The culture medium was replaced with $5 \%$ complete medium $24 \mathrm{~h}$ later and continuously cultured for 7-14 days. The BMSCs in the control group were also cultured for the same period. The cells in each group were seeded onto 6-well temperature-sensitive plates $\left(9.6 \mathrm{~cm}^{2}\right.$, Nunc Co., Tokyo, Japan) at a density of $6 \times 10^{8} /$ $\mathrm{cm}^{2}$. They were then cultured for $2-4$ days at $37^{\circ} \mathrm{C}, 5 \% \mathrm{CO}_{2}$, and saturated humidity. When substantial cell growth was observed, the cells were incubated at $20^{\circ} \mathrm{C}, 5 \% \mathrm{CO}_{2}$, and saturated humidity. Under these conditions, the cells gradually separate from the dish bottom, and 15 min later, the cells would shed and, together with the extracellular matrix, form a complete cell sheet. 
Table 1. Grouping of the treatments.

\begin{tabular}{l|l}
\hline Groups & Treatments \\
\hline A & BMSC sheets \\
\hline B & Transfected by Ad-CMV-eGFP BMSC sheets \\
\hline C & Transfected by Ad-CMV-hCDMP1-IRES-eGFP BMSC sheets \\
\hline
\end{tabular}

\section{Real-time polymerase chain reaction (RT-PCR)}

The cell sheets in each group were collected and total RNA was extracted with Trizol (Invitrogen Corp., CA, USA). RT-PCR was then performed in accordance with the SYBR fluorescence fuel method (Takara Co., Dalian, China). The cDNA was then synthesized using the two-step method of Applied Biosystems 7500 Real-Time PCR System ( $25 \mu \mathrm{L}$ system). The procedures were as follows: Stage 1 pre-denaturation: $95^{\circ} \mathrm{C}$ for $30 \mathrm{~s}$ and Stage 2 PCR amplification: $95^{\circ} \mathrm{C}$ for $5 \mathrm{~s}, 60^{\circ} \mathrm{C}$ for $34 \mathrm{~s}$, with a total of 40 cycles. Each gene sample was replicated in three different wells. The primer sequences used are shown in Table 2.

Table 2. Sequences of the primers used.
\begin{tabular}{l|l|c|c}
\hline Gene & Primer & Length (bp) & Tm $\left({ }^{\circ} \mathrm{C}\right)$ \\
\hline hCDMP1 & $\begin{array}{l}\text { Forward: 5'-AACAGCAGCGTGAAGTTGGAG-3' } \\
\text { Reverse: 5'-CAGGGCACTAATGTCAAACACGTA-3' }\end{array}$ & 123 & 50 \\
\hline GAPDH & $\begin{array}{l}\text { Forward: } \\
\text { Reverse: 5'-CGGTGGTGGACCTCATGGT-3' }\end{array}$ & 58 & 52 \\
\hline
\end{tabular}

$\mathrm{Tm}=$ melting temperature.

\section{Western blot}

The cell sheets of the three groups (Table 1) were collected for conventional sample preparation and bicinchoninic acid quantitation, followed by an SDS-polyacrylamide gel electrophoresis (Bio-Rad Laboratories, Inc., PA, USA). The proteins were then transferred onto polyvinylidene fluoride (PVDF) membranes (Nunc Co.), closure and film rinsing were performed followed by overnight hybridization with rabbit anti-human CDMP1 polyclonal antibody (Abcam Inc., MA, USA). After a thorough rinsing of the film, hybridization with goat anti-rabbit secondary antibody (Abcam Inc.) was performed, followed by development and photography of the film.

\section{Preparation of engineered cell sheets}

The cell sheets in each well were collected in accordance with a standard-operating protocol. A PVDF membrane (Sigma-Aldrich Corp.) was used to carefully transfer the monolayer cell sheets into another well with the culture medium discarded. In this way, the side of the loading cell sheet would come into contact with the cells on the bottom wall. Using this procedure, the absence of air bubbles could be ensured. One milliliter of complete medium was dripped onto the PVDF membrane, which was then cultured at $37^{\circ} \mathrm{C}, 5 \% \mathrm{CO}_{2}$, and saturated humidity. When the cell sheets were seen to separate from the PVDF membrane, the membrane was removed followed by continued culturing. The repetition of this step resulted in multilayer-overlapping tissue engineered cell sheets (Kobayashi et al., 2008). 


\section{Establishment of a thyroid cartilage defect animal model}

The rabbits were randomly divided into three groups. Four rabbits in each group were anesthetized by 3\% sodium pentobarbital injection (Fuzhou Maixin Biotechnology Development Co., Ltd., Fuzhou, China) through the ear vein $(30 \mathrm{mg} / \mathrm{kg})$. The rabbits were then fixed and, after routine disinfection and covering with a sterile towel, an anterior median longitudinal incision was performed to separate the skin and muscles, exposing the thyroid cartilage. A $0.5 \times 0.5-\mathrm{cm}$ full thickness cartilage defect that did not penetrate the laryngeal mucosa was prepared on the left side. The detailed procedures are referred to as "tissue engineering experimental techniques".

\section{Transplantation of tissue engineered cell sheets}

The prepared tissue engineered cell sheets of the three above mentioned groups were carefully transplanted into the thyroid cartilage defect rabbits. The edge was gently fixed with biological glue, we then used 7-0 non-damage suture fiber to suture the mucous and muscle. No. 1 suture fiber was used to close the incision, which was then disinfected and dressed. The animals' respiration, activities, and eating within postoperative $24 \mathrm{~h}$ were closely observed. The animals were fed a high-protein feed regularly and intramuscularly administered 1.6 million units of penicillin daily for five consecutive days. The stiches were removed 7-9 days later, and two rabbits from each group were sacrificed on weeks 4 and 8, respectively, after the operation.

\section{Type II collagen immunohistochemical staining and Alcian blue staining}

To study the tissue engineered cartilage sites, paraffin sections were prepared. The paraffin sections were created by dewaxing with xylene I, xylene II, an ethanol gradient (Sigma-Aldrich Corp.), followed by a water rinse. The sections were rinsed with PBS three times for $5 \mathrm{~min}$, and stained with $1 \%(\mathrm{v} / \mathrm{v})$ Alcian blue working fluid (Sigma-Aldrich Corp.) for 20-30 min. This was followed by a 2-s rinse with $0.05 \mathrm{M} \mathrm{HCl}$ (Sigma-Aldrich Corp.), 5 min nuclear fast red re-staining, and a 2-min rinse in tap water. The sections were then dried, dehydrated with an ethanol gradient (Sigma-Aldrich Corp.), hyalinized with xylene, and mounted with neutral gum (Shanghai Sangon Biological Engineering Co., Ltd., Shanghai, China). The dewaxed paraffin sections were rinsed in water. Subsequently, an endogenous peroxidase closure was performed; the sections were first cultured with primary antibody working fluid (Shanghai Sangon Biological Engineering Co., Ltd.) at $37^{\circ} \mathrm{C}$ for $30 \mathrm{~min}$, then the secondary antibody (Shanghai Sangon Biological Engineering Co., Ltd.) was added and cultured in a wet box at $4{ }^{\circ} \mathrm{C}$ overnight, followed by a final DAB staining (Sigma-Aldrich Corp.). The sections were then observed under a microscope (Leica Science Lab.).

\section{Statistical analysis}

IPP6.0 was used for image analysis and the SPSS16.0 software (SPSS Inc., IL, USA) was used for the statistical analyses. All data are reported as means \pm SD. 


\section{RESULTS}

\section{Cell culture and CDMP1 transfection}

The cultured primary BMSCs exhibited wall adherence within $24 \mathrm{~h}$. After the first medium exchange, the wall-adherent cells were short, spindle-like or triangular, and formed small colonies. The cells exhibited typical fibroblastic morphology 5-7 days later and connected with each other, forming a film arranged in a fish-like shape after 10-12 days. The cells transfected with CDMP1 exhibited flashing fluorescence, with a transfection efficiency reaching $80 \%$ (Figure 1).

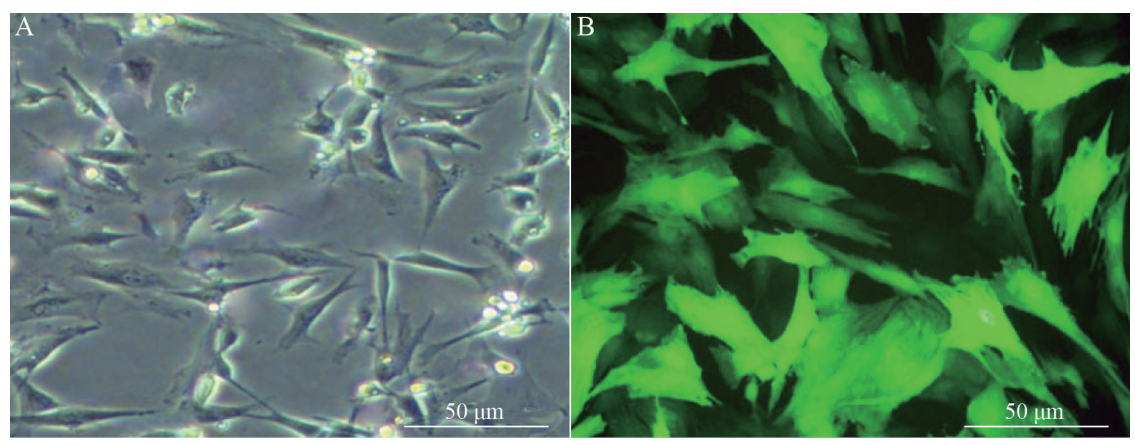

Figure 1. Appearance of BMSCs of passage 1 after culturing for $24 \mathrm{~h}(\mathbf{A})$ and BMSC appearance after transfecting by CDMP1 for $72 \mathrm{~h}(\mathbf{B})$. The magnification is $200 \mathrm{X}$ in both cases.

\section{Observation of cell sheets}

The cell sheets cultured on the temperature-sensitive dishes exhibited a complete structure. They were white and film-like and exhibited a certain toughness and maneuverability. The phase contrast microscopy revealed that the cells were tightly connected; as the intercellular matrix shrank, the intercellular space disappeared and morphological changes appeared. The cells were short and fusiform, with unclear boundaries. The multilayer overlapping cell sheets were closely connected with an increased toughness and a more stereo 3-D shape (Figure 2).

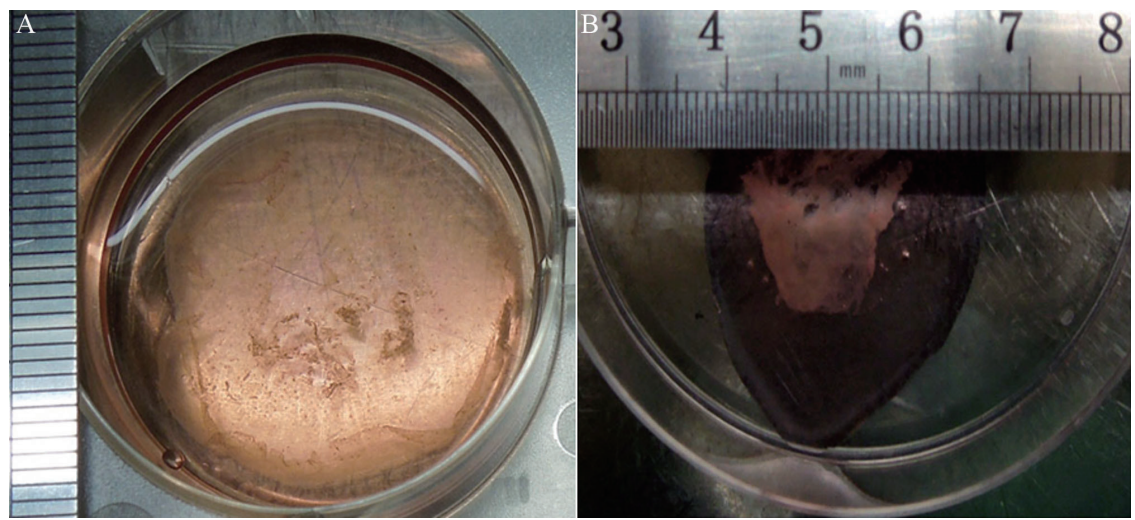

Figure 2. Appearance of cell sheets. A. BMSC sheet of monolayer; B. BMSC sheets of trilaminar. 


\section{Real-time PCR}

The amplification rates of CDMP1 and GAPDH were basically same (Figure 3A). By comparing the $\Delta \Delta \mathrm{Ct}$ values, the Applied Biosystems 7500 v. 2.0 .5 software automatically calculates the statistical values and provided the histograms shown in Figure 3B. This histogram illustrates the significant differences among the three groups $(\mathrm{P}<0.05)$.
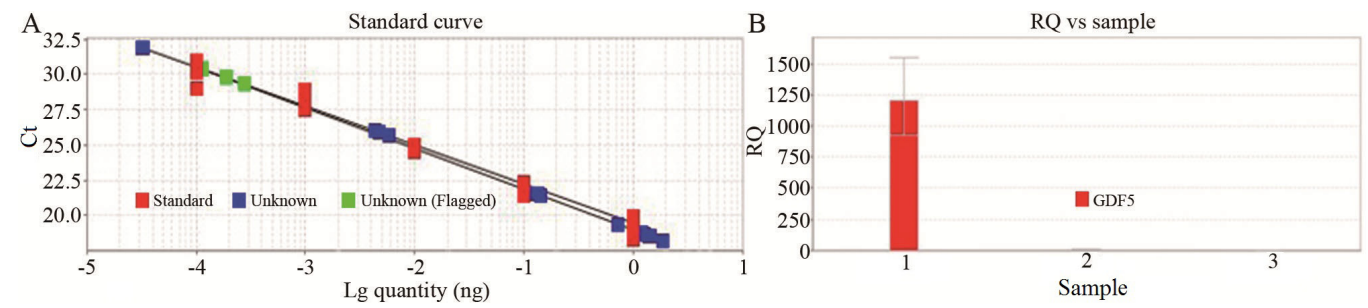

Figure 3. Identification of CDMP1 expression in transfected BMSC sheets. A. Standard curve of CDMP1 and GAPDH. B. Expression of CDMP1 in transfected BMSC sheets. Sample 1: group A; Sample 2: group B; Sample 3: group C. Ct, threshold cycle; RQ, relative quantity.

\section{Western blot}

Group A exhibited an obvious electrophoretic band with a molecular weight of about $13 \mathrm{kDa}$ (consistent with that of the hCDMP1 protein), while groups $\mathrm{B}$ and $\mathrm{C}$ showed no electrophoretic bands. The size of the internal control $\beta$-actin was about $43 \mathrm{kDa}$ (Figure 4).
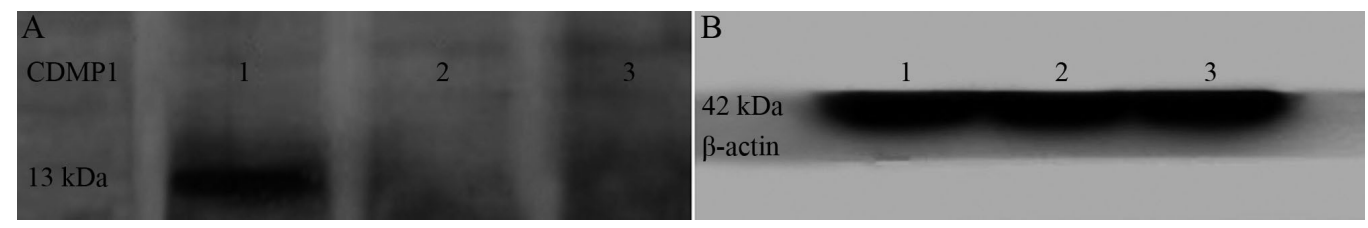

Figure 4. Expression of the CDMP1 protein in transfected BMSC sheets. Lane $1=$ group A; lane 2 = group B; lane 3 = group $\mathrm{C}$.

\section{Animal observations}

Animals were observed to eat 6-8 $\mathrm{h}$ after surgery. They exhibited no breathing difficulty, no unusual activity, and returned to normal behavior $24 \mathrm{~h}$ later. Furthermore, no significant decline in body weight was observed and the neck incision healed during first stage. The implant did not prolapse and showed no foreign substance or immune response.

\section{Observation after engineered cartilage surgery}

We observed no obvious wound infection or necrosis within 4 weeks after surgery. Group A exhibited a pink wound with a less smooth surface, which was very similar to 
the surrounding cartilage. Groups B and C showed obvious depressed wounds, with clear boundaries. Eight weeks after surgery, the observations of the wounds revealed a slightly gray wound in group A with cartilage-like changes and the surface was generally smooth with blurred boundaries. Groups B and C exhibited pink wounds that were slightly depressed, with soft texture and the boundaries with the surrounding, normal cartilage were still clear (Figure 5).

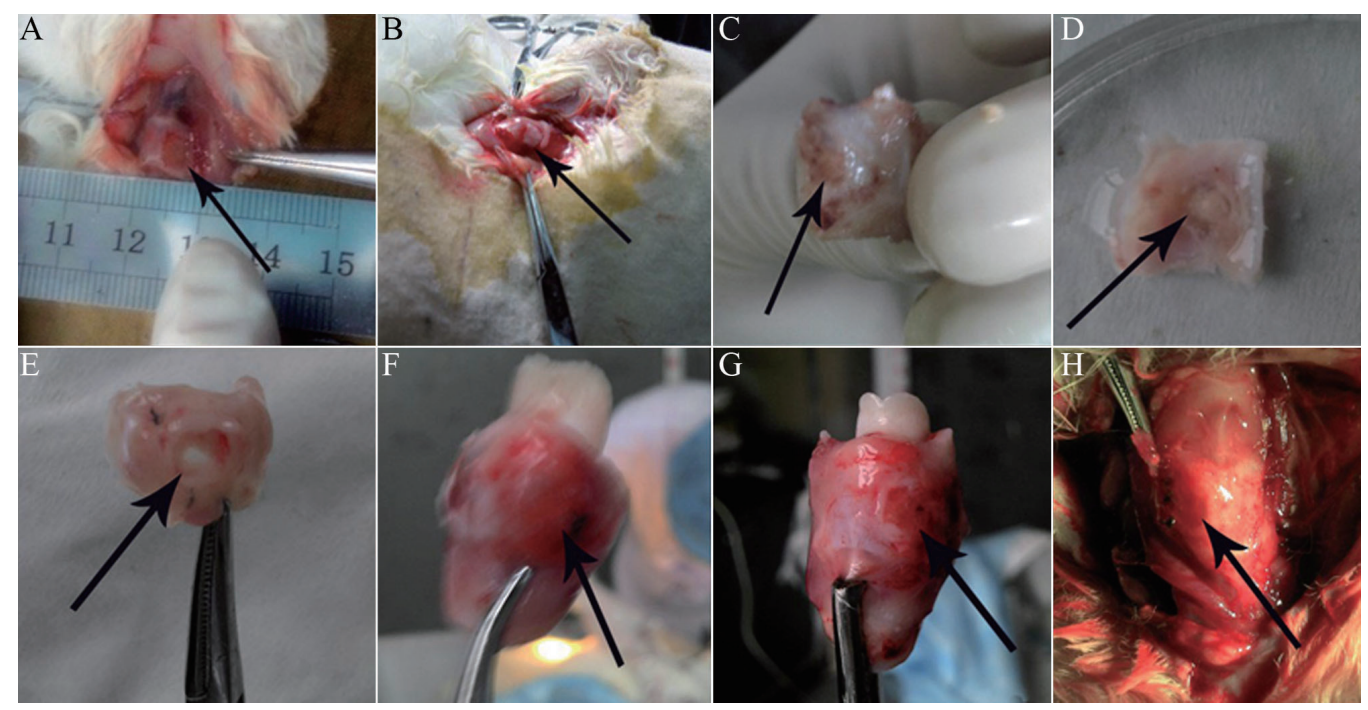

Figure 5. Observation of the acquired engineered cartilages. A. Model of rabbit thyroid cartilage defects; B. implantation of cell sheets; C. group A after 4 weeks; D. group B after 4 weeks; E. group C after 4 weeks; F. group A after 8 weeks; G. group B after 8 weeks; H. group C after 8 weeks. Arrows mean wound surface.

\section{Histological examination of the tissue engineered cartilage}

At 8 weeks after surgery, the engineered cartilage of group A exhibited the growth of large numbers of chondrocyte-like cells and type II collagen immunohistochemistry. The Alcian blue staining exhibited positive results. In groups B and C, we observed substantial replacement by fibrous scar tissue, as well as less muscle tissue. The type II collagen immunohistochemistry and Alcian blue staining were essentially negative (Table 3 and Figure 6).

Table 3. Expression of type II collagen protein and intensity analysis of proteoglycan (GAG) for the different groups.

\begin{tabular}{l|c|c}
\hline Group & Type II collagen protein & GAG \\
\hline A & $8655 \pm 1665$ & $15,046 \pm 1915$ \\
\hline B & $9516 \pm 304$ & $15,767 \pm 483$ \\
\hline C & $19,250 \pm 902^{*}$ & $28,196 \pm 749^{*}$ \\
\hline
\end{tabular}

Values highlighted with an asterisk are significant at $\mathrm{P} \leq 0.05$, compared with the control. 


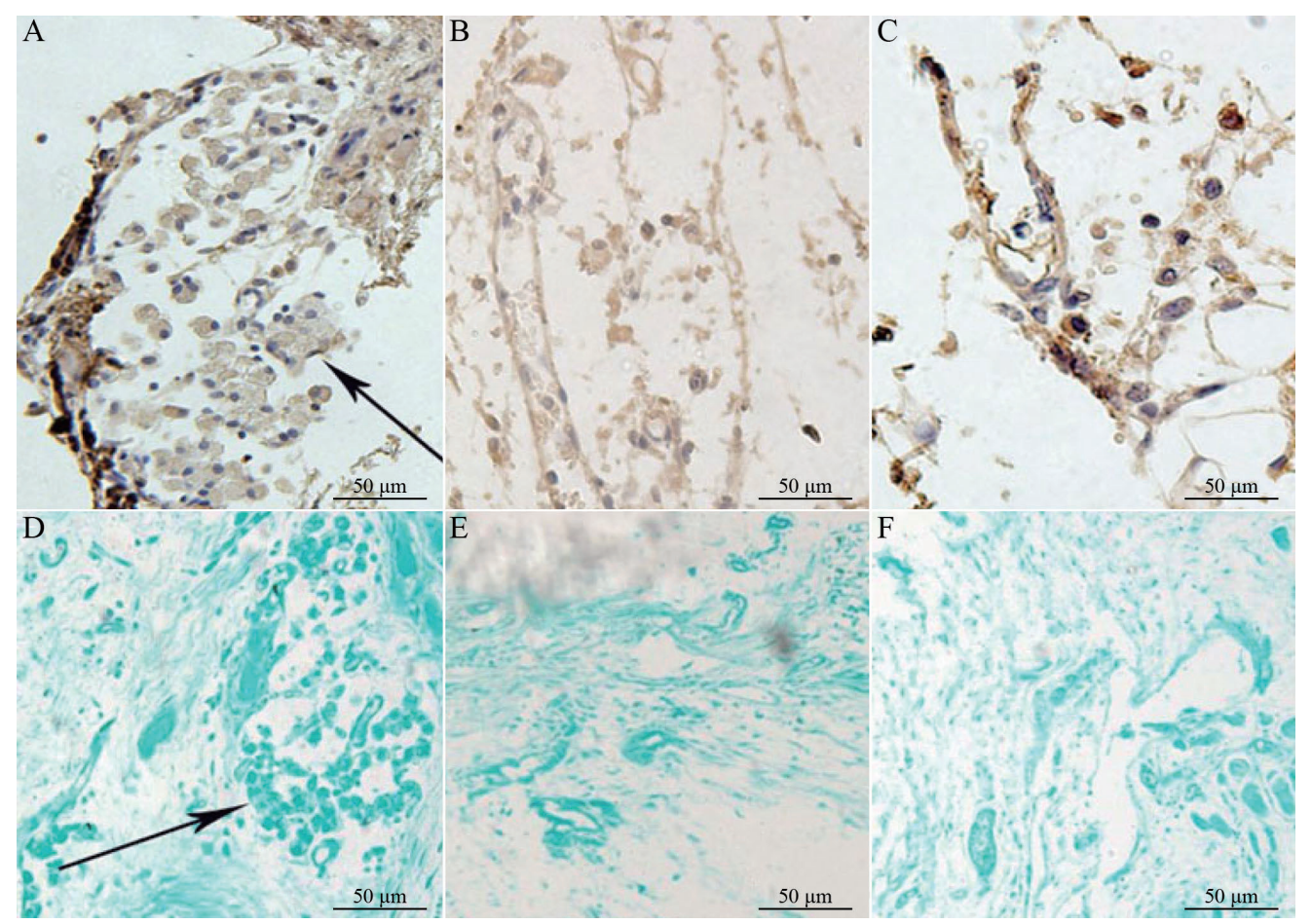

Figure 6. Expression of type II collagen protein and proteoglycan (GAG) for different groups (200X magnification). Expression of type II collagen protein by immunohistochemical staining of group A (A), group B (B), and group C (C); and expression of GAG by Alcian blue staining of group A (D), group B (E), and group C (F). Arrow in Figure A means type II collagen protein; arrow in Figure D means GAG.

\section{DISCUSSION}

Cell sheet technology has the following biological characteristics (Okano et al., 1993): 1) good biocompatibility; 2) suitable mechanical strength and ideal operability; 3) high cell inoculation rate, a rich and diverse matrix; and 4) could be quantitatively controlled to construct the needed size and thickness so that the constructed tissues resemble normal tissues. The basic principle is to use temperature-sensitive culture dishes (Fujita et al., 2012) to construct the cell sheets, and to use the amphiprotic temperature-sensitive characteristics to noninvasively harvest intact cell sheets (Yamato and Okano, 2004; Haraguchi et al., 2012). Thus, the enzymatic method can be avoided and the key cell surface proteins can be retained together with the growth factor receptors and cell ligandins. In this way, the cells obtained are more similar to natural tissue. Currently, this technology had been used to build tissues such as periodontal ligament, skin, blood vessels, cornea, and other tissues. It is also reaching an application in eye surface regeneration, myocardial repairing, and periodontal tissue regeneration (Basile et al., 2008; Gauvin et al., 2010; Takahashi et al., 2010; Klann and Koeppl, 2012; Takagi et al., 2012; Tang et al., 2012; Packer et al., 2013; Sekiya et al., 2013; Ye et al., 2013; Li et al., 2014; Sasagawa et al., 2014). Currently, the cells used in cell sheet 
engineering are mostly BMSCs, cardiomyocytes, and hepatocytes, and studies of transgenic cell sheets are rare.

CDMP1 is a recently discovered polypeptide growth factor, which has specific cartilage induction abilities. It is mainly expressed in the gathering area of the precartilage matrix during the embryonic period and in the cartilage core of developing long bones. Thus, it could induce cartilage formation. Presently, many studies have investigated the potential of CDMP1 in in vitro transplantation and in repairing cartilage defects and deformities. Some results have been obtained in respect to repairing tissues such as bone, tendons, ligaments, etc. (Post et al., 2013; Tatsumi et al., 2013; Abou Neel et al., 2014; Chen et al., 2014; Tang et al., 2014). However, exogenously added CDMP1 is not only very expensive, but has also shown a low bioavailability and a short effect time.

Based on previous studies, the present study aimed at testing whether, compared with BMSC sheets, CDMP-transfected BMSC sheets had a better cartilage repairing ability. We also wanted to examine whether CDMP-transfected BMSC sheets would be more effective in repairing cartilage defects. In this experiment, we used Ad-mediated transgene technology, to transfect CDMP into BMSCs. Following successful induction, a temperature-sensitive dish was used to harvest independent cell sheets, and to build a 3-D engineered cell sheet using 3-layer overlapping technology. This was then transplanted into animals to explore and identify the abilities of the cell sheets in repairing rabbit cartilage defects. Both general and histological aspects were investigated. Our aim was to combine genetic engineering, stem cell, and cell sheet technology, in order to explore the possibilities of reconstruction and regeneration of cartilage, with the hope of providing a new approach to and method for cartilage tissue engineering.

CDMP1 transgenic cell sheets exhibited significantly higher relative quantity than both the negative transfection group and the non-cell sheet transfected group. Based on the western blot, CDMP1 was expressed in the transgenic cell sheet group (13 kDa band). Groups B and C showed no such expression, confirming the successful transgenic induction technology at gene and protein levels. The general observations of the engineered cartilage obtained on weeks 4 and 8 after surgery revealed that group A exhibited a smooth wound with cartilage-like cells generated, and no clear boundaries with the surrounding, normal tissue. The type II collagen immunohistochemical and the Alcian blue staining were both positive. In contrast, groups B and $\mathrm{C}$ were filled with both fibrous and muscle tissue, the wound exhibited an obvious depression, the boundaries were clear, and both the type II collagen immunohistochemistry and Alcian blue staining were negative. This indicates that the CDMP1-transfected BMSC sheets had good cartilage differentiation activities, and could effectively repair rabbit cartilage defects.

This study combined cell sheet technology, genetic engineering, and tissue engineering, by using Ad to transfect CDMP1 into rabbit BMSCs and temperature-sensitive dishes to successfully construct transgenic cell sheets. We were thus able to avoid the damaging effects of trypsin digestion that traditional methods suffer from. The important cell surface proteins were therefore protected so that the differentiation activity of cells to cartilage was greatly preserved. This could be seen in the much more similar expression of type II collagen and proteoglycan with natural cartilage, and, thus, it effectively promoted the repairing of rabbit cartilage defects. Due to limitations in the experimental conditions, only short in vivo repairing of cartilage defects were observed. Whether the long-term effects are also satisfactory remains to be further investigated and our aim is to do so in future follow-up studies. 
Although the cell sheet technology is still in its infancy, there is a lack of long-term clinical observations, and many problems are still in need of solutions. Transgenic cell sheets could overcome the heterogeneous reactions inside traditional tissue engineering scaffolds and other defects. It could also improve the cells' abilities to directly differentiate in a certain direction. Thus, there is potential for a wider range of applications and cell sheet technology could be expected to open up a new path in tissue engineering.

\section{Conflicts of interest}

The authors declare no conflict of interest.

\section{ACKNOWLEDGMENTS}

Research supported by the Project of Liaoning Provincial Science and the Technology Foundation (\#2013020126-228, \#2013020126-221).

\section{REFERENCES}

Abou Neel EA, Chrzanowski W, Salih VM, Kim HW, et al. (2014). Tissue engineering in dentistry. J. Dent. 42: 915-928. http://dx.doi.org/10.1016/j.jdent.2014.05.008

Alshammary S, Fukushima S, Miyagawa S, Matsuda T, et al. (2013). Impact of cardiac stem cell sheet transplantation on myocardial infarction. Surg. Today 43: 970-976. http://dx.doi.org/10.1007/s00595-013-0528-2

Basile P, Dadali T, Jacobson J, Hasslund S, et al. (2008). Freeze-dried tendon allografts as tissue-engineering scaffolds for Gdf5 gene delivery. Mol. Ther. 16: 466-473. http://dx.doi.org/10.1038/sj.mt.6300395

Chen T, Wang Y, Bu L and Li N (2014). Construction of functional tissue-engineered bone using cell sheet technology in a canine model. Exp. Ther. Med. 7: 958-962.

Du CH, Li NY, Gao N, Yao C, et al. (2013). A preliminary study on the application of bone marrow stromal cell sheet on the formation of functional tissue-engineered bone in dogs. J. Oral Maxillofac. Surg. 71: 1531.e1-1531.e10. http:// dx.doi.org/10.1016/j.joms.2013.04.029

Fujita J, Itabashi Y, Seki T, Tohyama S, et al. (2012). Myocardial cell sheet therapy and cardiac function. Am. J. Physiol. Heart Circ. Physiol. 303: H1169-H1182. http://dx.doi.org/10.1152/ajpheart.00376.2012

Gauvin R, Ahsan T, Larouche D, Lévesque P, et al. (2010). A novel single-step self-assembly approach for the fabrication of tissue-engineered vascular constructs. Tissue Eng. Part A 16: 1737-1747. http://dx.doi.org/10.1089/ten. tea. 2009.0313

Haraguchi Y, Shimizu T, Sasagawa T, Sekine H, et al. (2012). Fabrication of functional three-dimensional tissues by stacking cell sheets in vitro. Nat. Protoc. 7: 850-858. http://dx.doi.org/10.1038/nprot.2012.027

Klann M and Koeppl H (2012). Spatial simulations in systems biology: from molecules to cells. Int. J. Mol. Sci. 13: 77987827. http://dx.doi.org/10.3390/ijms 13067798

Kobayashi H, Shimizu T, Yamato M, Tono K, et al. (2008). Fibroblast sheets co-cultured with endothelial progenitor cells improve cardiac function of infarcted hearts. J. Artif. Organs 11: 141-147. http://dx.doi.org/10.1007/s10047-008$\underline{0421-8}$

Li G, Wang X, Cao J, Ju Z, et al. (2014). Coculture of peripheral blood CD34+ cell and mesenchymal stem cell sheets increase the formation of bone in calvarial critical-size defects in rabbits. Br. J. Oral Maxillofac. Surg. 52: 134-139. http://dx.doi.org/10.1016/j.bjoms.2013.10.004

Muraoka M, Shimizu T, Itoga K, Takahashi H, et al. (2013). Control of the formation of vascular networks in 3D tissue engineered constructs. Biomaterials 34: 696-703. http://dx.doi.org/10.1016/j.biomaterials.2012.10.009

Okano T, Yamada N, Sakai H and Sakurai Y (1993). A novel recovery system for cultured cells using plasma-treated polystyrene dishes grafted with poly(N-isopropylacrylamide). J. Biomed. Mater. Res. 27: 1243-1251. http://dx.doi. org $/ 10.1002 / \mathrm{jbm} .820271005$

Packer C, Boddice B and Simpson S (2013). Regenerative medicine techniques in cardiovascular disease: where is the horizon? Regen. Med. 8: 351-360. http://dx.doi.org/10.2217/rme.13.21 
Post MJ, Rahimi N and Caolo V (2013). Update on vascularization in tissue engineering. Regen. Med. 8: 759-770. http:// dx.doi.org/10.2217/rme.13.74

Sasagawa T, Shimizu T, Sekiya S, Yamato M, et al. (2014). Comparison of angiogenic potential between prevascular and non-prevascular layered adipose-derived stem cell-sheets in early post-transplanted period. J. Biomed. Mater. Res. A 102: 358-365. http://dx.doi.org/10.1002/jbm.a.34707

Sekiya S, Shimizu T and Okano T (2013). Vascularization in 3D tissue using cell sheet technology. Regen. Med. 8: 371377. http://dx.doi.org/10.2217/rme.13.16

Takagi R, Yamato M, Kanai N, Murakami D, et al. (2012). Cell sheet technology for regeneration of esophageal mucosa. World J. Gastroenterol. 18: 5145-5150.

Takahashi H, Nakayama M, Yamato M and Okano T (2010). Controlled chain length and graft density of thermoresponsive polymer brushes for optimizing cell sheet harvest. Biomacromolecules 11: 1991-1999. http://dx.doi.org/10.1021/ bm100342e

Takezawa T, Mori Y and Yoshizato K (1990). Cell culture on a thermo-responsive polymer surface. Biotechnology (N. Y.) 8: 854-856. http://dx.doi.org/10.1038/nbt0990-854

Tamaki T, Soeda S, Hashimoto H, Saito K, et al. (2013). 3D reconstitution of nerve-blood vessel networks using skeletal muscle-derived multipotent stem cell sheet pellets. Regen. Med. 8: 437-451. http://dx.doi.org/10.2217/rme.13.30

Tang ZL, Akiyama Y and Okano T (2012). Temperature-responsive polymer modified surface for cell sheet engineering. Polymers (Basel) 4: 1478-1498. http://dx.doi.org/10.3390/polym4031478

Tang ZL, Akiyama Y and Okano T (2014). Recent development of temperature-responsive cell culture surface using poly(N-isopropylacrylamide). J. Polym. Sci., B, Polym. Phys. 52: 917-926. http://dx.doi.org/10.1002/polb.23512

Tatsumi K, Sugimoto M, Lillicrap D, Shima M, et al. (2013). A novel cell-sheet technology that achieves durable factor VIII delivery in a mouse model of hemophilia A. PLoS One 8: e83280. http://dx.doi.org/10.1371/journal.pone.0083280

Wu G, Cui Y, Wang YT, Yao M, et al. (2014a). Repair of cartilage defects in BMSCs via CDMP1 gene transfection. Genet. Mol. Res. 13: 291-301. http://dx.doi.org/10.4238/2014.January.17.14

Wu G, Cui Y, Ma L, Pan X, et al. (2014b). Repairing cartilage defects with bone marrow mesenchymal stem cells induced by CDMP and TGF- $\beta 1$. Cell Tissue Bank. 15: 51-57. http://dx.doi.org/10.1007/s10561-013-9369-x

Yamato M and Okano T (2004). Cell sheet engineering. Mater. Today 7: 42-47. http://dx.doi.org/10.1016/S1369$\underline{7021(04) 00234-2}$

Ye K, Felimban R, Moulton SE, Wallace GG, et al. (2013). Bioengineering of articular cartilage: past, present and future. Regen. Med. 8: 333-349. http://dx.doi.org/10.2217/rme.13.28 